\title{
Hartley Slater
}

\section{BACK TO ARISTOTLE!}

\begin{abstract}
There were already confusions in the Middle Ages with the reading of Aristotle on negative terms, and removing these confusions shows that the four traditional Syllogistic forms of statement can be readily generalised not only to handle polyadic relations (for long a source of difficulty), but even other, more measured quantifiers than just 'all', 'some', and 'no'. But these historic confusions merely supplement the main confusions, which arose in more modern times, regarding the logic of singular statements. These main confusions originate in the inability of the mainline modern tradition to supply the 'logically proper names' which alone have the right to replace individual variables; an inability which has resulted in the widespread, but erroneous replacement of individual variables with ordinary proper names, i.e. names for contingent beings, in many if not most contemporary logic texts. The paper includes the exhibition and grammatical characterisation of the logically proper names that are required instead, specifying just how they differ syntactically from ordinary proper names. It also shows how ontologically significant is the distinction, since not only do logically proper names refer to necessarily existent objects (showing there are no 'empty domains' for Classical Logic to fail to apply to), but also thereby central features of Realism become considerably clarified.
\end{abstract}

Keywords: logically proper names, Aristotelian logic, Classical logic, free logic

\section{The Right Square}

In this paper I investigate how it came to be that Aristotelian Syllogistic lost ground to the logic developed by Peirce and Frege. This is puzzling because there are very close similarities between Aristotle's original work on singular statements and a main theme in Modern Logic: Russell's 
Theory of Descriptions. But it also highly curious because the points that have to be made to defend Aristotle are in the main very elementary, and quite well known. The following, for instance, is Aristotle's account of the traditional Square of opposition ([3], [1, 126]):
(A) All S is P:
$(x)(\mathrm{S} x \supset \mathrm{P} x) \&(\exists x) \mathrm{S} x$
(i.e., 'Any $\mathrm{S}$ is $\mathrm{P}$ ' + 'there are $\mathrm{Ss}^{\prime}$ ')
(E) No $\mathrm{S}$ is $\mathrm{P}$ :
$(x)(\mathrm{S} x \supset \neg \mathrm{P} x)$
(I) Some $\mathrm{S}$ is $\mathrm{P}$ :
$(\exists x)(\mathrm{S} x \& \mathrm{P} x)$
(O) Not all $\mathrm{S}$ is $\mathrm{P}$ :
$(\exists x)(\mathrm{S} x \& \neg \mathrm{P} x) \vee \neg(\exists x) \mathrm{S} x$
(Some $\mathrm{S}$ is not $\mathrm{P}: \quad(\exists x)(\mathrm{S} x \& \neg \mathrm{P} x)$ )

As can be seen, the original account involves separating internal negatives from external ones. But also it can be generalised to more measured quantifiers and to relational expressions, like 'Some boys love every girl', as we shall soon see.

The Boolean tradition has forgotten Aristotle (and natural language), with the result that the internal/external negation distinction has been lost, and the general forms get misunderstood. Thus 'all' becomes 'any', and 'not all' becomes 'some not'. But also thereby the above generalisations disappear as well. For the proper Aristotelian forms are representable in probabilistic terms - (A) $\operatorname{pr}(\mathrm{P} x / \mathrm{S} x)=1$, (I) $\operatorname{pr}(\mathrm{S} x \& \mathrm{P} x)>$ $0,(\mathrm{E}) \operatorname{pr}(\mathrm{S} x \& \mathrm{P} x)=0,(\mathrm{O}) \operatorname{pr}(\mathrm{P} x / \mathrm{S} x) \neq 1$ - and that allows in other probabilistic expressions.

On Aristotle's analysis the positive forms A and I carry existential import but the negative forms $\mathrm{E}$ and $\mathrm{O}$ do not. So the law of Obversion does not hold. Thus XEY does not imply XA $\neg \mathrm{Y}$, and XOY does not imply XI $\neg \mathrm{Y}$. The lack of implication in the latter case, for instance, is because the $\mathrm{O}$ form is now read with an external negation: 'Not all Xs are Ys', in place of 'Some Xs are not Ys', which has an internal or predicate negation. 'Not all $\mathrm{Xs}_{\mathrm{s}}$ are $\mathrm{Ys}_{\mathrm{s}}$ ' is then the disjunction of 'Some Xs are not Ys' and 'No Xs are Ys' (or 'There are no Xs'). Also Contraposition does not hold: XAY does not imply $\neg \mathrm{YA} \neg \mathrm{X}$, and $\mathrm{XOY}$ does not imply $\neg \mathrm{YO} \neg \mathrm{X}$. The former result resolves, amongst other things, Hempel's Paradox of Confirmation, through the non-equivalence between 'All ravens are black' and 'All non-black things are non-ravens'.

All this derives from the fact that Aristotle distinguished external from internal negations. What has come down to us from antiquity is a mix of Aristotle's account together with additions, principally about negative terms, first provided by Boethius. For Boethius equated external 
negations with internal ones. This was copied by Buridan, amongst others in the later middle ages, although how the discrepancy with Aristotle survived the re-translation of the original texts initiated by St Thomas is something of a mystery. But the totality of this tradition is not viable at all, once one takes a more rigorous look at it than the medievals evidently did. Boole, for instance, initiated the now common 'positive and negative existential' tradition which had to abandon most of the relations in the traditional Square of Opposition. More ironically, since Boole was attempting a joint theory of logic and probability, this tradition lost sight of the proper connection between logic and probability.

For there are other, quite decisive reasons why the Aristotelian interpretation has to be kept. First there is supporting evidence for the original Aristotelian interpretation of universal statements when one considers other quantifiers. Thus 'Almost all Xs are Ys', 'Most Xs are Ys', and 'A lot of Xs are Ys' surely all entail 'Some Xs are Ys'. Also 'Not a lot of Xs are Ys', for instance, unlike 'A few Xs are not Ys', allows it to be possible that no $\mathrm{Xs}_{\mathrm{s}}$ are $\mathrm{Ys}_{\mathrm{s}}$ (or that there are no Xs at all). So, unlike when there is an internal negation, there is no entailment from the form with the external negation to 'Some Xs are not Ys'. But clearly, also, a probabilistic analysis of the Aristotelian forms supports the original reading. For $\operatorname{pr}(\mathrm{Y} x / \mathrm{X} x)=1$ entails $\operatorname{pr}(\mathrm{Y} x \& \mathrm{X} x)>0$. But $\operatorname{pr}(\mathrm{Y} x / \mathrm{X} x) \neq 1$ does not entail $\operatorname{pr}(\neg \mathrm{Y} x \& \mathrm{X} x)>0$, since it is possible that $\operatorname{pr}(\mathrm{X} x)=0$, in which case the conditional probability is not defined. The probabilistic analysis is applicable also, of course, to many other quantifiers. Thus 'Most Xs are Ys' can be represented as ' $\operatorname{pr}(\mathrm{Y} x / \mathrm{X} x)>\frac{1}{2}$ ', and 'Few Xs are not Ys' can be represented as ' $\operatorname{pr}(\neg \mathrm{Y} x / \mathrm{X} x)<\frac{1}{2}$ '.

But neither other quantifiers, nor a probabilistic interpretation are widely considered. Concentration on existential quantifiers and their negations has taken over most of the public's attention. As a result, one supposed difficulty with Aristotelian Syllogistic has continued to be thought insuperable: its seeming restriction to monadic predicate logic. In this respect the polyadic logics developed by Peirce and Frege were taken to win out. How could Aristotelian Syllogistic be extended to handle relational expressions like 'All boys love some girls', for example? That has been taken to be a great stumbling block. But not only can probabilistic analyses easily handle such cases; they also can be easily generalised to many other quantifiers. Thus 'All boys love some girls' is ' $\operatorname{pr}([\operatorname{pr}(\mathrm{L} x y / \mathrm{G} y)>0] / \mathrm{B} x)=1$ ', and 'Most boys love few girls' is $' \operatorname{pr}\left(\left[\operatorname{pr}(\mathrm{L} x y / \mathrm{G} y)<\frac{1}{2}\right] / \mathrm{B} x\right)>\frac{1}{2}$ '. (If probabilities are measured as pro- 
portions of existent cases - as in 'balls in urns' examples — there is no theoretical problem with the nested probabilities.)

\section{The Singular Case}

But there are even more misunderstandings when we come to look at the singular case. The singular case is where $(x)(y)((\mathrm{S} x \& \mathrm{~S} y) \supset x=y)$ : Socrates is well: $(\exists x)(\mathrm{S} x \& \mathrm{~W} x)$ (also: $(x)(\mathrm{S} x \supset \mathrm{W} x) \&(\exists x) \mathrm{S} x)$

Socrates is ill: $(\exists x)(\mathrm{S} x \& \mathrm{C} x \& \neg \mathrm{W} x)$ (where $(x)(\mathrm{W} x \supset \mathrm{C} x)$ )

Socrates is not ill: $(x)((\mathrm{S} x \& \mathrm{C} x) \supset \mathrm{W} x)$

Socrates is not well: $(x)(\mathrm{S} x \supset \neg \mathrm{W} x)$ (also: $(\exists x)(\mathrm{S} x \& \neg \mathrm{W} x) \vee \neg(\exists x) \mathrm{S} x)$

This was Aristotle's account, involving two contraries spanning a category (' $\mathrm{C} x$ ' is perhaps ' $\mathrm{x}$ is animate' in the case above). It again involves separating internal negatives from external ones. In general form this was also Russell's account, and Quine's account, as we shall see, and, most importantly, in all cases 'Socrates is well' is not of the form ' $\mathrm{W} x$ '.

The common contemporary analysis of 'Socrates is well' as being of the form 'Wx' forgets Russell and Quine, although it was encouraged by them through their failure to present sentences of the form ' $\mathrm{W} x$ '. Just what is of the form ' $\mathrm{W} x$ ' will appear later in this paper. In brief, a sentence is of the form ' $\mathrm{W} x$ ' only if ' $x$ ' refers to a necessary existent, which happens if ' $x$ ' is a Hilbertian epsilon term rather than a Russellian iota term. The distinction has several large consequences.

How do Russell and Quine come into the picture? Aristotle, as above, applied the distinction between external and internal negations to singular statements involving contrary terms, saying specifically that both 'Socrates is well' and 'Socrates is ill' would be false if 'Socrates does not exist' was true. Natural language supports Aristotle: if someone says 'My pen is in the drawer' and you look in the drawer and find no pen or only the pens of others, then you may say 'It is not in the drawer'; in doing so you leave the existence of the pen open, in contrast to when you say the contrary remark 'It is outside the drawer'. Taking 'Socrates' to be a 'disguised description', and so like 'my pen', in the manner of Russell, this shows that Russell's analysis of definite descriptions (which was also Quine's) followed the same line of analysis (though without explicit reference to contrary terms). Thus, for Russell, 'The king of France is bald' entails 'Some king of France is bald', and it has two negatives. For 
what we may write 'It is not the case that the king of France is bald' does not entail 'The king of France is not bald'. The former expression contains an external negation, and so a 'secondary occurrence' of the subject term. It is true if the king of France does not exist. The latter expression contains an internal, or predicate negation, and so a 'primary occurrence' of its subject term. It is false if the king of France does not exist, and since kings are in the right category the 'not bald' in this case can be replaced by the contrary to 'bald', namely 'hirsute'.

However, in addition to the medieval mix-ups with negative terms, another aspect of Russell's theory seems to have obscured the proper Aristotelian interpretation. For in symbols 'The king of France is bald' is, of course, on Russell's account:

$$
(\exists x)(\mathrm{K} x \&(y)(\mathrm{K} y \supset y=x) \& \mathrm{~B} x) .
$$

'The king of France is not bald' is then the same with ' $\neg$ ' before the last ' $\mathrm{B}$ ', and 'It is not the case that the king of France is bald' is the same with a ' $\neg$ ' before the initial ' $(\exists x)$ '. Trouble starts because Russell introduced 'iota terms' to symbolise these things another way. Amongst other things this seems to have influenced the tradition of Free Logic in a way we shall look at briefly later. But it also seems to have affected even more substantially the tradition in Classical, i.e. Fregean Logic. For Russell also wrote, making 'the king of France' look like an individual term, 'The king of France is bald' as 'B $\iota y K y$ ', i.e. ' $(\exists x)(x=\iota y \mathrm{~K} y \& \mathrm{~B} x)$ '. In these terms the form with the internal negative, 'The king of France is not bald' becomes ' $(\exists x)(x=\iota y \mathrm{~K} y \& \neg \mathrm{B} x)$ '. And the form with the external negative, 'It is not the case that the king of France is bald' becomes ' $\neg(\exists x)(x=\iota y \mathrm{~K} y \& \mathrm{~B} x)$ '.

The problem is that in the formal symbolism we only have ' $\mathrm{B} x$ ' and its contradictory ' $\neg \mathrm{B} x$ ' as elementary forms, so evidently if elementary statements about 'the king of France' have a fourfold logic then 'the king of France' cannot be identical to any ' $x$ ' in the given identities. As should be well known, an ordinary name for a contingent individual such as 'Socrates', is not a 'logically proper name', and only such are proper substitutes for variables. In Russell's terms, the definite description 'the king of France' is not a 'complete symbol' for an individual. To get the logic right with ordinary names one has to employ individuating descriptions such as 'pegasises' in Quine's example, or simply treat 'is Pegasus' as involving the 'is' of predication rather than identity. 
These points have been well rehearsed, but they are not always remembered, it seems. Because of that they suggest a major contemporary reason why, by contrast, the Aristotelian scheme has been lost sight of in recent times. For, despite Russell and Quine, it is very common to find ordinary proper names in the place of the variables in modern logic texts, both classical and free. This makes it seem that they have just a binary logic, whereas they have a fourfold one, as in Aristotle. And why are ordinary proper names so often found in the place of variables? Surely the fault must lie with Russell's use of iota terms in identities. For while insisting that only logically proper names should be put in the place where individual variables go, he not only used the confusing iota-term symbolism, making it seem that such terms were complete symbols, but he also provided no examples of complete symbols. Certainly he made some suggestions about them in his lectures on Logical Atomism, but he never provided a formal account. Quine even held that the quantified forms involving 'pegasises' could not have instantiations, so that the burden of reference was carried just by general pronouns such as 'someone'.

The faultiness of these positions is reinforced once one realises that there is no difficulty in finding the appropriate complete individual terms in Classical Logic. For one classical theorem in predicate logic, for instance, is:

$$
(\exists x)((\exists y) \mathrm{K} y \supset \mathrm{K} x) .
$$

So the existence of certain objects is guaranteed, and in the epsilon calculus they are given names: epsilon terms. Thus (see [2])

$$
(\exists y) \mathrm{K} y \supset \mathrm{K} \epsilon x \mathrm{~K} x,
$$

is a theorem there, and

$$
(\exists y)(y=\epsilon x \mathrm{~K} x)
$$

is also a theorem there. But the Russellian

$$
(\exists y)(y=\iota x \mathrm{~K} x)
$$

still isn't. For it is contingent whether anyone is a sole king of France, but what is not contingent is that there is something that is a sole king of France if anything is a sole king of France. If Russell had presented such complete terms, then no-one following him would have had an excuse to put ordinary proper names in place of variables, and the fourfold 
logic of ordinary proper names, and much more, would have been better appreciated.

For many other things are revealed once we have logically proper names in the form of epsilon terms. Thus it is sometimes said that Classical Logic 'assumes the domain is not empty', and sometimes free logics are constructed that supposedly lack this assumption. How can one get, for instance, ' $\mathrm{Fa}$ ' for some ' $\mathrm{a}$ ' from ' $(x) \mathrm{F} x$ ' — couldn't there be no entities for ' $x$ ' to range over in the universal quantifier? But 'there is a king' is entailed by 'it is a king' (no matter what 'it' is), and also entails 'it is a king' if the 'it' refers to one of the objects alluded to in the existential remark. It is this necessary equivalence that is formalised in the epsilon calculus theorem:

$$
(\exists x) \mathrm{K} x \equiv \mathrm{K} \epsilon x \mathrm{~K} x .
$$

That shows there is invariably some object associated with an existential remark, but by introduction of negations that theorem also means that

$$
(x) \mathrm{K} x \equiv[\neg(\exists x) \neg \mathrm{K} x \equiv \neg \neg \mathrm{K} \epsilon x \neg \mathrm{K} x \equiv] \mathrm{K} \epsilon x \neg \mathrm{K} x .
$$

So there is also invariably some object associated with a universal remark, and ' $\epsilon x \neg \mathrm{K} x$ ' will do as the ' $\mathrm{a}$ ' needed above. That, of course, still leaves free logics to be constructed where the related 'a's are ordinary proper names, although most extant free logics do not respect the fourfold logic of such names in the manner required by Aristotle, Russell, and Quine - or ordinary language.

But there are even deeper, ontological consequences deriving from distinguishing logically proper names from ordinary proper names. For it becomes evident that individuals, i.e. what the variables in such expressions as ' $K x$ ' vary over, must have eternal existence. So they must be separated from any entities that merely have 'existence' in this world, or some other. What, indeed, in relation to individuals, has 'existence' just in this world, or just in some other - making them 'physical objects', and 'fictions', respectively — are identifying properties. To highlight the difference even more, we can say that Aristotelian Realism holds for such physical objects/fictions, whereas Platonic Realism holds for the associated individuals. It is more usual, perhaps, to think of Platonic Realism and Aristotelian Realism as being rivals, in opposition to one another, because they are seemingly differing accounts of the same thing. But in the present connection we come to see that they are 
merely complementary, through being concerned with different things: identifying properties that may or may not be instantiated, and the eternally existing individuals in which those identifying properties (and other properties) may be instantiated.

The point is illustrated most clearly in the epsilon calculus theorem (see $[2,417]$ ) showing that

$$
(\exists x)(\mathrm{K} x \&(y)(\mathrm{K} y \supset y=x) \& \mathrm{~B} x)
$$

(i.e. 'There is a sole king of France, who is bald') is equivalent to

$$
(\exists x)(\mathrm{K} x \&(y)(\mathrm{K} y \supset y=x)) \& \mathrm{~B} \epsilon x(\mathrm{~K} x \&(y)(\mathrm{K} y \supset y=x)),
$$

(i.e. 'There is a sole king of France. He is bald'). For the first conjunct in the second expression is about certain identifying properties being instantiated. That is what must hold for a sole king of France to exist (contingently). But the second conjunct there is about a certain eternally existing individual - one that is a sole king of France if there is such a thing, but which still exists even if there is no such thing: the supposed king of France.

But not only through presenting Russell's formula as a conjunction do we enable a separation to be made between a true or false assertion about this world, namely the first conjunct delimiting existence and uniqueness conditions, and a further assertion, in the second conjunct, which is made about its subject independently of whether the first conjunct is true or false, and so about something that exists eternally. For, as the detail of the grammatical expression 'the supposed king of France' for the logically proper name indicates, the same point is central to understanding how such eternally real objects are accessed — a seemingly perennial difficulty with Platonic entities. Paradigmatically the situation is represented again in the epsilon variant to Russell's analysis of 'The king of France is bald'. Thus while the above epsilon variant to Russell's ' $(\exists x)(\mathrm{K} x \&(y)(\mathrm{K} y \supset y=x) \& \mathrm{~B} x)$ ', is

$$
(\exists x)(\mathrm{K} x \&(y)(\mathrm{K} y \supset y=x)) \& \mathrm{~B} \epsilon x(\mathrm{~K} x \&(y)(\mathrm{K} y \supset y=x)),
$$

the first conjunct ' $(\exists x)(\mathrm{K} x \&(y)(\mathrm{K} y \supset y=x))$ ' is itself equivalent to

$$
\mathrm{K} \epsilon x(\mathrm{~K} x \&(y)(\mathrm{K} y \supset y=x)) \&(y)(\mathrm{K} y y=\epsilon x(\mathrm{~K} x \&(z)(\mathrm{K} z \supset z=x))) .
$$

So access to the individual $\epsilon x(\mathrm{~K} x \&(z)(\mathrm{K} z \supset z=x))$ is provided entirely by means of the linguistic act of supposing there is a sole king 
of France, and through its then being invariably possible to cross-refer to the same individual from within further assertions. Eternal objects, in this way, are simply subjects of discourse.

\section{References}

[1] Prior, A. N., 1962, Formal Logic, O.U.P., Oxford.

[2] Slater, B.H., 2009, "Hilbert's epsilon calculus and its successors", pages 385-448 in: D. Gabbay and J. Woods (eds.) Handbook of the History of Logic, vol. 5, Elsevier Science, Burlington MA.

[3] Thompson, M., 1953, "On Aristotle's square of opposition", Philosophical Review 62: 251-265.

Hartley Slater

University of Western Australia

hartley.slater@uwa.edu.au 